\title{
A PSICOMOTRICIDADE ATRELADA AO LÚDICO NA TERCEIRA IDADE
}

\author{
PSYCHOMOTRICITY RELATED TO PLAY IN THE THIRD AGE
}

\section{PSICOMOTRICIDAD RELACIONADA CON EL JUEGO EN LA TERCERA EDAD}

\author{
Gabriele Priscila Dias \\ Graduada em Pedagogia pelas Faculdades Integradas de Jahu \\ Pós Graduada em Psicopedagogia pelas Faculdades Integradas de Jahu \\ e-mail: gabrielepd@hotmail.com
}

\begin{abstract}
Suselaine A. Zaniolo Mascioli
Pós-Doutora em Educação - sub-área: Educação Infantil - UFSCAr. Pesquisadora Integrante do "Núcleo de Estudos e Pesquisas sobre a Escola de Vigostky" - Neevy - UFSCar e do GEERERI Grupo de Estudos "Educação e Relações Étnico-Raciais na Temática Indígena".

Docente: FIJ- Faculdades Integradas de Jáu; UNIP -Universidade Paulista.

E-mail: suse.zaniolo@gmail.com
\end{abstract}

\begin{abstract}
RESUMO
O envelhecimento é acompanhado por modificações biológicas, fisiológicas, bioquímicas, químicas, psicológicas, sociais, do poder físico e econômico. As diversas alterações que acompanham essa fase da vida do indivíduo não devem ser vistas apenas como perdas, mas como etapas que se abrem a novas oportunidades e a novas potencialidades que podem ser exploradas. O processo de envelhecimento populacional concomitante ao aumento da expectativa de vida, traz consigo o desafio de criar condições para que o prolongamento da vida se dê com bem-estar, assim as atividades lúdicas envolvendo a psicomotricidade visam um envelhecer com qualidade, pois, promovem a manutenção da qualidade de vida dos idosos, além do aumento da autoestima. Partindo desse pressuposto, o objetivo deste trabalho foi analisar as contribuições da psicomotricidade para o campo da gerontologia por meio de atividades lúdicas, bem como explorar as atividades psicomotoras e lúdicas no intuito de promover a manutenção da qualidade de vida dos idosos, além do aumento da autoestima. Realizou-se uma pesquisa qualitativa de cunho bibliográfico, elaborada a partir de livros, teses, dissertações e publicações científicas em meio eletrônico, abarcando as áreas da gerontologia, psicomotricidade e ludicidade.
\end{abstract}

Palavras-chave: Psicomotricidade. Ludicidade. Idoso.

\footnotetext{
ABSTRACT

Aging is accompanied by biological, physiological, biochemical, chemical, psychological, social modifications of physical and economic power. The various changes that accompany this phase of an individual's life should not only be seen as losses, but as stages that open to new opportunities and new potentials that can be exploited. The process of population aging

RELEDUC | ISE | v. 37 | n. 1 | dez. 2020
} 
concomitant with increased life expectancy brings with it the challenge of creating conditions for the prolongation of life to be well-being, so the playful activities involving psychomotricity aim at a quality aging, therefore, promote the maintaining the quality of life of the elderly, as well as increasing self-esteem. Based on this assumption, the objective of this study was to analyze the contributions of psychomotricity to the field of gerontology through playful activities, as well as to explore the psychomotor and playful activities in order to promote the maintenance of the elderly's quality of life, as well as increasing self-esteem. A qualitative bibliographic research was carried out, elaborated from books, theses, dissertations and scientific publications in electronic media, covering the areas of gerontology, psychomotricity and playfulness.

Keywords: Psychomotricity. Playfulness. Elderly.

\section{RESUMEN}

El envejecimiento es un proceso que va acompañado de modificaciones biológicas, fisiológicas, bioquímicas, químicas, psicológicas, sociales, del poder físico y económico. Las distintas alteraciones que acompañan esa fase de la vida del individuo no deben ser vistas solo como perdidas, pero como etapas que se abren a nuevas oportunidades y a nuevas potencialidades que pueden ser exploradas. El proceso de envejecimiento de la población simultáneo al aumento de la expectativa de vida, trae consigo el reto de crear condiciones para que la prolongación de la vida ocurra con bienestar. De esta manera, las actividades lúdicas involucrando la psicomotricidad, buscan un envejecer con calidad, ya que promueven la manutención de la calidad de vida de los ancianos además del aumento de la autoestima. Saliendo de ese presupuesto, el objetivo de este trabajo fue analizar las contribuciones de la psicomotricidad para el campo de la gerontología a través de actividades lúdicas, así como explorar las actividades psicomotoras y lúdicas con el intuito de promover la manutención de la calidad de vida de los ancianos, además de aumentar la autoestima. Se realizó una investigación cualitativa de carácter bibliográfico, desarrollada a partir de libros, tesis, disertaciones y publicaciones científicas en medios electrónicos, abarcando las áreas de la gerontología, psicomotricidad y del lúdico.

Palabras clave: Psicomotricidad. Lúdico. Anciano.

\section{INTRODUÇÃO}

A expectativa de vida é um processo que vem aumentando com o decorrer do tempo. No Brasil é acompanhado por modificações no perfil de saúde da população e predomínio de doenças crônicas e limitações funcionais.

De acordo com o Instituto Brasileiro de Geografa e Estatística (IBGE, 2018), as novas projeções apontam a transição da estrutura etária, com a mudança de uma pirâmide populacional de base larga (rejuvenescida) para uma pirâmide de base estreita e de topo ampliado (envelhecida). O envelhecimento populacional é a transformação da estrutura etária que acontece em decorrência do aumento da proporção de idosos no conjunto da população e a

$$
\text { RELEDUC | ISE } \stackrel{88}{8} \text { v. } 3 \mid \text { n. } 1 \mid \text { dez. } 2020
$$


consequente diminuição da proporção de jovens. Durante mais de 500 anos, o Brasil teve uma estrutura etária rejuvenescida. Mas isto vai mudar no decorrer do século XXI.

À medida que o ser humano envelhece, quer continuar tendo força, resistência, flexibilidade e mobilidade para permanecer ativo e independente de modo a poder atender as próprias necessidades pessoais e domésticas, como fazer compras ou participar de atividades recreativas e esportivas. (RIKLI; JONES, 2008).

Para o favorecimento de tais fatores a psicomotricidade é sugerida como meio propiciador de qualidade de vida, através de atividades psicomotoras adaptadas à faixa etária, visto que a psicomotricidade baseia-se em uma concepção unificada da pessoa, que inclui as interações cognitivas, sensoriomotoras e psíquicas na compreensão das capacidades de ser e de expressar-se, a partir do movimento, em um contexto psicossocial. Ela se constitui por um conjunto de conhecimentos psicológicos, fisiológicos, antropológicos e relacionais que permitem, utilizando o corpo como mediador, abordar o ato motor humano com o intuito de favorecer a integração deste sujeito consigo e com o mundo dos objetos e outros sujeitos. (COSTA, 2002).

De acordo com Moura e Camargos (2005) o lúdico, por sua vez, é uma alternativa importante para estimulação pessoal e valorização do indivíduo. Serve como instrumento para a promoção da saúde quando apresentado na temática de educação em saúde, e prevenção das incapacidades e dependência quando apresentado em atividades físicas e intelectuais.

Com base nessas premissas, o artigo teve como intuito estudar a velhice, bem como destacar atividades psicomotoras e lúdicas como meio de manutenção da qualidade de vida dos idosos, para tal, o trabalho foi desenvolvido analisando as contribuições da psicomotricidade para o campo da gerontologia por meio de atividades lúdicas, compreendendo o processo histórico do envelhecimento, os benefícios da metodologia lúdica e sua aplicabilidade como estratégia na promoção da saúde do sujeito idoso e manutenção da qualidade de vida, analisando como as atividades psicomotoras podem ser aliadas no desenvolvimento motor, cognitivo e corporal dos idosos, e explorando as atividades psicomotoras e lúdicas no intuito de promover a manutenção da qualidade de vida dos idosos, além do aumento da autoestima.

Diante do exposto percebe-se que para se ter um envelhecimento bem sucedido, não basta apenas que o idoso almeje viver bem. É necessário que se tenham estímulos específicos e programas preventivos que lhe favoreçam viver da melhor forma possível. Nesse sentido o intuito deste trabalho é expandir os conhecimentos de modo a contribuir para a melhoria da qualidade de vida desses indivíduos.

$$
\text { RELEDUC | ISE | v. } 39 \text { | n. } 1 \text { | dez. } 2020
$$




\section{DESENVOLVIMENTO}

\subsection{Envelhecimento}

De acordo com Diniz, Fuentes e Cosenza (2013) o envelhecimento, ou senescência, é um processo universal, determinado geneticamente para os indivíduos da espécie, é um processo irreversível, que inicia ao nascermos e termina com a morte, motivo pelo qual é também chamado de envelhecimento normal.

O envelhecimento pode ser classificado em primário que é um processo gradual e inevitável de deterioração física que começa cedo na vida e continua ao longo dos anos, não importa o que as pessoas façam para evitá-lo. Nessa visão, o envelhecimento é uma consequência inevitável de ficar velho. E envelhecimento secundário, resultado de doenças, abusos e maus hábitos, fatores que em geral podem ser controlados. (BUSSE, 1987; J.C. HORN E MEER, 1987 APUD PAPALIA, FELDMAN, 2013, p. 573).

Segundo a Organização Mundial de Saúde (OMS, 2015), o envelhecimento cronológico se dá a partir dos 60 anos, estando os idosos classificados em três outras faixas: de 60 a 69 anos estão os jovens idosos; de 70 a 79 anos, os meio idosos; e, a partir dos 80 anos, os idosos velhos.

A população brasileira está em trajetória de envelhecimento e, até 2060, o percentual de pessoas com mais de 65 anos passará dos atuais 9,2\% para 25,5\%. Ou seja, 1 em cada 4 brasileiros será idoso. É o que aponta projeção realizada pelo Instituto Brasileiro de Geografia e Estatística. (IBGE, 2018).

Segundo a pesquisa, a fatia de pessoas com mais de 65 anos alcançará $15 \%$ da população já em 2034, ultrapassando a barreira de 20\% em 2046. Em 2010, estava em 7,3\%.

A pesquisa mostra que em 2039 o número de idosos com mais de 65 anos superará o de crianças de até 14 anos, o que acelerará a trajetória de envelhecimento da população. Atualmente, a população com até 14 anos representa 21,3\% dos brasileiros e cairá para 14,7\% até 2060, segundo o IBGE (2018). Já a faixa entre 15 e 64 anos, que hoje responde por 69,4\% da população, cairá para 59,8\% em 2060.

Com o aumento da longevidade da população torna-se necessário a aplicação e criação de políticas públicas capazes de satisfazer e amparar essa nova faixa populacional, atualmente a Política Nacional do Idoso, Lei n ${ }^{\circ}$ 8.842, regulamentada em 1994 e, o Estatuto do Idoso, Lei $\mathrm{n}^{\mathrm{o}}$ 10.741, promulgado em 2003, asseguram os direitos sociais dos idosos e propiciam condições para promover a autonomia, integração e participação efetiva dos mesmos na 
sociedade (BRASIL, 2004)

$\mathrm{O}$ artigo $2^{\circ}$ do Estatuto do Idoso discorre que:

O idoso goza de todos os direitos fundamentais inerentes à pessoa humana, sem prejuízo da proteção integral de que se trata esta lei, assegurando-se lhe, por meio da lei ou por outros meios, todas as oportunidades e facilidades, para preservação de sua saúde física e mental e seu aperfeiçoamento moral, intelectual, espiritual e social, em condições de liberdade e dignidade. (BRASIL, 2003)

O Artigo $4^{\circ}$ constitui diretrizes da política nacional do idoso e prevê:

I - viabilização de formas alternativas de participação, ocupação e convívio do idoso, que proporcionem sua integração às demais gerações;

II - participação do idoso, através de suas organizações representativas, na formulação, implementação e avaliação das políticas, planos, programas e projetos a serem desenvolvidos;

III - priorização do atendimento ao idoso através de suas próprias famílias, em detrimento do atendimento asilar, à exceção dos idosos que não possuam condições que garantam sua própria sobrevivência;

IV - descentralização político-administrativa;

$\mathrm{V}$ - capacitação e reciclagem dos recursos humanos nas áreas de geriatria e gerontologia e na prestação de serviços;

VI - implementação de sistema de informações que permita a divulgação da política, dos serviços oferecidos, dos planos, programas e projetos em cada nível de governo;

VII - estabelecimento de mecanismos que favoreçam a divulgação de informações de caráter educativo sobre os aspectos biopsicossociais do envelhecimento;

VIII - priorização do atendimento ao idoso em órgãos públicos e privados prestadores de serviços, quando desabrigados e sem família;

IX - apoio a estudos e pesquisas sobre as questões relativas ao envelhecimento. (BRASIL, 1994)

A sociedade, o estado e a família entram em cena como agentes necessários e capazes de responder e corresponder às expectativas e necessidades surgidas com as mudanças, referentes aos cuidados dos idosos que perdem sua autonomia para o desempenho de atividades antes corriqueiras e enfrentam uma série de limitações. (SILVA, 2015).

De acordo com Alves (2013) na velhice o sujeito se depara com inúmeras perdas, de ordem biológica, social e psicológica. Dentre as perdas biológicas estão: problemas de coluna, ossos (osteoporose), lentidão nos movimentos, tremores, flacidez, ressecamento da pele, rugas e manchas, os cabelos se tornam quebradiços, ocorre a calvície e as unhas crescem mais devagar.

Os idosos apresentam também baixo desempenho em tarefas que requeiram iniciativa, controle, planejamento e avaliação de comportamentos complexos, além da diminuição do 
desempenho intelectual, memória, capacidade de resolução de problemas e percepção, tendo alguns parâmetros mais deteriorados que outros. Consequentemente, o desequilíbrio emocional se instala, a autoestima diminui, o que pode promover o adoecer psíquico do idoso, assim como as principais síndromes psiquiátricas: síndromes depressivas, mentais, orgânicas, delirantes, neuroses, distúrbios ansiosos, somatoformes e dissociativos, distúrbios pelo uso de substâncias psicoativas e distúrbios do sono. (VELASCO, 2006).

A morte social também ocorre com a pessoa idosa. Começa-se com o isolamento dessa pessoa, por não permitirem seu ingresso em algumas atividades da vida diária e acabam por a excluírem. Por conta de tais circunstância, acontece a morte física, sem movimentos, sem utilização do corpo e da mente e, por fim, acontece a morte biológica onde tudo se acaba. (ALVES, 2013).

O envelhecimento, processo marcado por diversas mudanças em âmbito motor, psíquico, cognitivo e social, deve ser tratado e trabalhado em suas potencialidades. A pessoa idosa apresenta potencialidades, e isso deve ser reconhecido. Como processo de adaptação e, consequentemente, de desenvolvimento e melhoria da qualidade de vida, as capacidades físicas podem ser exercitadas e desenvolvidas através de uma prática regular, diminuindo ou retardando perdas determinadas pelo processo de envelhecimento. (SESC, 2005).

Segundo Alves (2013) as atividades físicas devem estar associadas as atividades sociais, pois as atividades sociais contribuirão para o redescobrimento da alegria, espontaneidade e reintegração dos idosos à sociedade.

\title{
2.2 A psicomotricidade e o lúdico voltados à terceira idade
}

A Psicomotricidade baseia-se em uma concepção unificada da pessoa, que inclui as interações cognitivas, sensoriomotoras e psíquicas na compreensão das capacidades de ser e de expressar-se, a partir do movimento, em um contexto psicossocial. Ela se constitui por um conjunto de conhecimentos psicológicos, fisiológicos, antropológicos e relacionais que permitem, utilizando o corpo como mediador, abordar o ato motor humano com o intuito de favorecer a integração deste sujeito consigo e com o mundo dos objetos e outros sujeitos. (COSTA, 2002).

O termo "psicomotricidade" surgiu em 1920 com Ernest Dupré, mas foi Henri Wallon, o pioneiro da Psicomotricidade no campo cientifico. Atualmente tende a ser reconceituada, em razão do seu objeto de estudo, isto é o homem através do movimento nas relações com seu mundo interno e externo.

\author{
RELEDUC | ISE | v. 32 | n. 1 | dez. 2020
}


A psicomotricidade pode ser classificada em duas linhas de pensamento a relacional e a funcional. A psicomotricidade relacional utiliza o brincar como alavanca do processo de aprendizagem. Negrine (1995) fundamenta essa pratica, a qual chama de pratica psicomotriz educativa, defendendo a ideia de que o jogo (o brincar) só é jogo quando possui um elemento simbólico, de faz de conta. Falkenbach (2002) define que a pratica psicomotriz educativa:

Deve permitir às crianças a exploração corporal diversa do espaço, dos objetos e materiais; facilitar a comunicação das crianças por intermédio da expressividade motriz; potencializar as atividades grupais, também favorecer a liberação de emoções e conflitos por intermédio do vivenciamento simbólico (p.77).

A psicomotricidade funcional é baseada no trabalho com as funções motoras, das quais destacam-se esquema corporal, lateralidade, estruturação espacial e a orientação temporal, as quais são apontadas por Meur (1989) como necessária para a organização da percepção. Mattos (2000) também destaca a importância dessas quatro funções, associando o esquema corporal como conhecimento de si, a estruturação espacial como conhecimento do meio e a orientação temporal como conhecimento das relações com o meio.

Além das duas linhas de pensamento, a psicomotricidade também apresenta três vertentes, a reeducação psicomotora que busca reeducar o corpo para que este reproduza movimentos motores de acordo com o padrão esperado; a terapia psicomotriz que considera as emoções do corpo, pois utiliza as bases da psicanálise para trabalhar o indivíduo como um todo e a educação psicomotora ou pratica psicomotriz educativa que busca o desenvolvimento global do indivíduo através do lúdico facilitando sua socialização e auxiliando no processo de aprendizagem.

As experiências motoras são abundantes em relação aos corpos jovens, mas o tempo e a sociedade impõem a depreciação dos gestos motores dos corpos mais velhos, por acharem que já não conseguem ser utilizados, contribuindo assim, para a perda do bem estar, no entanto a pratica psicomotora começa com o nascimento e permanece por todos os momentos da vida de uma pessoa. E ao idoso dá a oportunidade de desenvolver-se através do movimento além de englobar valores como partilhar, agir, respeitar, aprender e reaprender. (ALVES 2013).

Barreto (2000) afirma que a psicomotricidade consiste na integração do indivíduo, utilizando, para isso, o movimento e levando em consideração os aspectos relacionais ou afetivos, cognitivos e motrizes.

Segundo Alves (2013) por meio das vivencias psicomotoras, a população idosa pode 
manter sua independência e autonomia sobre sua vida, o que favorece a reestruturação dos problemas de ordem física e mental, emocional e social, vivendo de forma ativa e participativa, buscando sempre um olhar simbólico na realização de suas atividades e, dessa forma, considerando o processo de envelhecimento com mais tranquilidade.

O trabalho psicomotor leva o idoso a ter a consciência e a reapropriação do uso de seu corpo, tanto no que diz respeito à sua funcionalidade como também à sua capacidade de expressão. A atividade corporal, através de sensações proprioceptivas, permite o resgate de sensações vividas e conquistadas, propiciando a conscientização e a superação dos limites anteriormente predeterminados pelas falhas de sua memória. (GALVANI; SILVEIRA, 2016).

De acordo com Alves (2013) o idoso tem que descobrir o espaço perdido, conscientizarse de sua importância como pessoa que possui um espaço e que pode se manter por meio da sua forma própria de viver. Ele tem de ter a consciência e o conhecimento que a vida não pode fazêlo contrair-se e se proibir, achando que tudo que é feito pelo corpo é perigoso e assim deixar de utiliza-lo. O idoso tem que ter a certeza que seu corpo ainda pode e deve realizar muitas coisas e valorizar cada uma delas.

A psicomotricidade explora a expressão corporal, desenvolvendo sua habilidade motora e também o aspecto cognitivo, afetivo e social. E é nesse ponto em que psicomotricidade e ludicidade se encontram pois as atividades lúdicas envolvem os movimentos corporais e as atividades psicomotoras envolvem o brincar e o jogo. (CASTIGLIA, PIRES, BOCCARDI, 2006).

A palavra lúdico é derivada do latim "ludus", que significa jogo e está relacionada com o divertimento, $\mathrm{o}$ ato de brincar e com a recreação. Por tratar-se de uma forma dinâmica o lúdico permite o aparecimento de comportamentos naturais, possibilitando ao ser humano desfrutar dos mais variados sentimentos, tais como: medo, contentamento, tensão, aflição, entre outros. (CICERO, 2007).

$\mathrm{Na}$ terceira idade as atividades lúdicas trazem benefícios psicológicos, melhoram a autoestima e o relacionamento social, estimulam a criatividade a memória e o autoconhecimento. KISHIMOTO enfatiza que:

No lúdico o idoso não é mais do que é na realidade, permitindo-lhe o aproveitamento de todo o seu potencial. Nele o idoso toma iniciativa, planeja, executa, avalia. Enfim, ele aprende a retomar decisões, a introjetar o seu contexto social na temática do faz de conta. Ele aprende a se reeducar. O poder simbólico lúdico do faz de conta abre um espaço para a apreensão de significados de seu contexto e oferece alternativas para novas conquistas no seu mundo imaginário. (KISHIMOTO,1993, p.35). 
De acordo com Carvalho (2009) exercitar-se, pensar, raciocinar, estimular tanto a mente como o corpo através de atividades lúdicas e jogos é fundamental para manter o organismo saudável. Jogos que mexem com a memória fotográfica são excelentes para aprimorar e exercitar as funções cognitivas, além de serem prazerosos como atividade grupal. A ludicidade aliada à estimulação cognitiva se torna uma arma fundamental na luta contra a falta de estímulo mental que muitos idosos sofrem. Trazer brincadeiras e jogos que eles já vivenciaram em situações anteriores faz com que sintam prazer em voltar a se sentirem crianças.

Por tratar-se de uma forma dinâmica o lúdico permite o aparecimento de comportamentos naturais, possibilitando ao ser humano desfrutar dos mais variados sentimentos, tais como: medo, contentamento, tensão, aflição, entre outros. (CÍCERO, 2007).

$\mathrm{O}$ ato de brincar simula e integra a vida social contribuindo com o desenvolvimento do ser humano, seja criança ou adulto, pois o lúdico colabora para que o ser humano se torne ativo melhorando a interação no meio social, ou seja, aprimora o convívio com outras pessoas, o desenvolvimento de novos saberes profissionais, pessoais e culturais. (HUIZINGA,1996).

Alves (2013) ressalta que nunca é tarde para novas descobertas, para realizar-se por meio do corpo, resgatando tudo aquilo que não conseguiu experienciar ao longo da vida, percebendo o que esse corpo pode pôr em prática descobrindo as belezas e o que cada pessoa deve e pode ser.

\subsection{Atividades psicomotoras lúdicas}

Segundo Velasco (2006) As relações corporais entre idosos sofrem uma série de barreiras, estabelecidas pelos valores em sua formação, pelas dificuldades motoras e funcionais, pela inibição e baixa autoestima e até mesmo pela falta de sociabilidade no grupo. São oportunidades em que a psicomotricidade se faz presente em tempo integral, através de propostas motivadoras e lúdicas.

O idoso poderá encontrar, nas brincadeiras e nos jogos, uma ferramenta de vida, comunicação e relacionamento. $\mathrm{O}$ homem nunca perde o desejo de brincar, verifica-se que a maturidade faz diminuir, mas felizmente, nunca desaparece. As atividades físico-recreativas são identificadas constantemente como uma das intervenções de saúde mais significativa na vida dos idosos. Dentre os benefícios imediatos, pode-se citar: maiores níveis de eficácia, controle interno, melhoria na qualidade do sono e relaxamento muscular. Do ponto de vista psicológico, a recreação lúdica tem um sentimento de ganho e satisfação de vida, redução da

$$
\text { RELEDUC | ISE | v. } 3 \text { | n. } 1 \text { | dez. } 2020
$$


tensão, melhora na autoimagem e autoestima e estados de animo positivos, contribuindo, também através da psicomotricidade, a uma maior liberdade de movimentos. (VELASCO, 2006).

Velasco (2006) apresenta algumas propostas de atividades lúdicas envolvendo a psicomotricidade e a ludicidade, no intuito de promover a manutenção da qualidade de vida dos idosos, além do aumento da autoestima.

Porém é pertinente salientar que de acordo com o grupo que realizará as atividades, algumas adequações são necessárias, em função da mobilidade e do interesse do grupo, tratando-se portanto de uma proposta de atividades aberta.

Velasco (2006) propõe as seguintes atividades:

- Automassagem: Nesta vivência o idoso desenvolverá sua sensibilidade por meio do toque (ou autotoque), no rosto, percorrendo o corpo até os pés, tal experiência promove calma, consciência corporal, autopercepção e conforto aos participantes.

- Outra estratégia para as vivencias corporais são o teatro e a dança, que oferecem um contanto mais íntimo com a arte. O teatro objetiva o trabalho de voz, respiração, desinibição, expressão corporal, atenção e memória, através de informações, textos e dinâmicas. A dança resgata a expressividade natural, desperta a sensibilidade, promove a socialização, a imaginação e a criatividade.

- O artesanato, a pintura, o desenho, a culinária, trabalham a motricidade fina e são estratégias sublimes de intervenção com idosos que ficam surpresos com sua produtividade e elevam sua autoestima ao finalizarem suas atividades e se reconhecerem capazes.

As atividades devem favorecer a autonomia, a liberdade de escolha, expressão e experimentação.

\section{CONSIDERAÇÕES FINAIS}

O aumento da estimativa de vida da população no Brasil repercute diretamente no crescimento da população idosa. Diante desse novo cenário, buscou-se através desse artigo inserir a psicomotricidade e a ludicidade como aliadas na manutenção de um envelhecimento saudável. 
A manutenção de um idoso mais ativo, desfrutando de uma identidade própria, de dignidade, alegria e participação social, favorecem com que essa fase da vida seja vivida com maior intensidade e que o envelhecimento seja bem sucedido dentro das suas possiblidades.

O envelhecimento é uma fase de inúmeras transformações que ocorrem causando decréscimo das funções orgânicas do idoso, perda da autoestima e isolamento. Para se ter um envelhecimento bem sucedido, não basta apenas que o idoso almeje viver bem, é necessário que se tenham estímulos específicos e programas preventivos que lhe favoreçam viver da melhor forma possível.

Dessa forma fica evidente a importância das atividades lúdicas envolvendo a psicomotricidade aplicadas a terceira idade, pois as mesma visam um envelhecer com qualidade, promovendo a manutenção da qualidade de vida dos idosos. Ressalta-se no entanto que qualquer atividade realizada com idosos devem respeitar suas limitações e seu ritmo.

Diferentes abordagens podem ser realizadas com o idoso, tanto em grupos, quanto em atividades individualizadas. Podem ser utilizados jogos de memória, jogos de tabuleiro, cruzadinhas, brincadeiras, caça-palavras, atividades manuais, dentre outras tantas, que certamente proporcionarão novas sinapses, auxiliarão no enfrentamento da perda cognitiva, o que trará maior motivação, disposição e autoconfiança.

Além de ser fonte de aprendizagens e reaprendizagens as atividades psicomotoras e lúdicas devem procurar promover o bem-estar, o acolhimento emocional, promovendo a dignidade e desenvolvendo um acolhimento humanizado ao idoso, buscando resgatar sua autonomia.

É necessário reconhecer que o idoso, apesar de possuir certa limitação de suas habilidades físicas e sensoriais, possui outras qualidades que podem ser igualmente importantes e estas devem ser estimuladas.

Conclui-se portanto que as atividades psicomotoras e as atividades lúdicas são aliadas na qualidade de vida dos idosos, ressalta-se no entanto que esse estudo não finaliza as discussões sobre esse tema, pois ainda há muito a acrescentar na área da psicomotricidade e ludicidade voltadas à terceira idade.

\section{REFERÊNCIAS}

ALVES, F. A psicomotricidade e o idoso: Uma educação para a saúde. Rio de Janeiro: WAK Editora, 2013. 
BARRETO, S. J. Psicomotricidade, educação e reeducação. 2.ed. Blumenau: Livraria Acadêmica, 2000.

BRASIL. Estatuto do idoso: lei federal n 10.741, de 01 de outubro de 2003. Brasília, DF: Secretaria Especial dos Direitos Humanos, 2004. Disponível em:

$<$ https://presrepublica.jusbrasil.com.br/legislacao/98301/estatuto-do-idoso-lei-10741-03\#art2>. Acesso em: 26 set. 2019.

BRASIL. Política Nacional do Idoso lei no 8.842, de 04 de Janeiro de 1994. Brasília, DF. Disponível em: <http://www.planalto.gov.br/ccivil_03/leis/18842.htm>. Acesso em: 27 set. 2019.

CASTIGLIA, R da C; PIRES, M.M; BOCCARDI, D. Interação social do idoso frente a um programa de formação pessoal. Revista Brasileira de Ciências do Envelhecimento Humano, Passo Fundo, p. 38-50, jan/jun. 2006. Disponível em: <http://seer.upf.br/index.php/rbceh/article/view/58/51>. Acesso em: 12 set. 2019.

CARVALHO, N. C. Dinâmicas para Idosos. Petrópolis: Vozes, 2009. Disponível em: https://books.google.com.br/books?id=rNUbBAAAQBAJ\&printsec=frontcover\&dq=din $\% \mathrm{C} 3$ $\%$ A2micas+para+idosos\&hl=ptBR\&sa=X\&ved=0ahUKEwjWqczg_9_kAhUkA9QKHV_Bn UQ6AEIKDAA\#v=onepage $\& \mathrm{q}=\mathrm{din} \% \mathrm{C} 3 \% \mathrm{~A} 2 \mathrm{micas} \% 20$ para $\% 20 \mathrm{idosos} \& \mathrm{f}=$ false. Acesso em: 26 set. 2019.

CÍCERO, M. T. Saber envelhecer: A amizade. Porto Alegre: L\&PM, 2007.

COSTA, A. C. Psicopedagogia e psicomotricidade: Pontos de intersecção nas dificuldades de aprendizagem. Petrópolis: Vozes, 2002.

DINIZ, M. F. L; FUENTES. D; COSENZA, M. R (org.). Neuropsicologia do envelhecimento: uma abordagem multidimensional. Porto Alegre: Artmed, 2013.

FALKENBACH, A. P. A educação física na escola: uma experiência como professor. Lajeado: UNIVATES, 2002.

GALVANINI, C; SILVEIRA, N.D.R. Longevidade e psicomotricidade: envelhecer com qualidade de vida. In: FONSECA, S.C. (org). O Envelhecimento ativo e seus fundamentos. São Paulo: Portal Edições, 2016. p. 418- 442. Disponível em: $<$ https://www.pucsp.br/sites/default/files/download/posgraduacao/programas/gerontologia/eb ook_-_livro_o_envelhecimento_ativo_e_seus_fundamentos.pdf >. Acesso em: 26 set. 2019.

HUIZINGA, R. Homo Ludens: O jogo como elemento de cultura. 4 ed. São Paulo: Perspectiva S.A, 1996.

IBGE - INSTITUTO BRASILEIRO DE GEOGRAFIA E ESTATÍSTICA. Projeção da População (revisão 2018), Rio de Janeiro. Disponível em $<$ https://www.ibge.gov.br/estatisticas-novoportal/sociais/populacao/9109-projecao-dapopulacao.html?=\&t=o-que-e $>$. Acesso em: 30 jan. 2019.

$$
\text { RELEDUC | ISE | v. } 3 \text { | n. } 1 \text { | dez. } 2020
$$


KISHIMOTO, T. M. O jogo e a educação infantil. São Paulo: Pioneira, 1993.

MATTOS, M. G de. Educação física infantil: construindo o movimento na escola. Guarulhos, SP: Phorte Editora, 2000.

MEUR, A de. Psicomotricidade: educação e reeducação. São Paulo: Manole, 1989.

MOURA, L.F; CAMARGOS, A.T. Atividades educativas como meio de socialização de idosos institucionalizados. Anais Universidade Federal de Minas Gerais. Minas Gerais. 2005

NEGRINE, A da S. Aprendizagem e desenvolvimento infantil: psicomotricidade, alternativas pedagógicas. Porto Alegre: Prodil, 1995.

OMS - ORGANIZAÇÃO MUNDIAL DE SAÚDE. Relatório mundial de envelhecimento e saúde. 2015. Genebra, Suíça. Disponível em: < https://www.who.int/es/news-room/factsheets\#R>. Acesso em: 13 set. 2019.

PAPALIA, D. E; FELDMAN, D. R. Desenvolvimento humano. 12. ed. Porto Alegre: AMGH, 2013.

RIKLI, R. E; JONES, C. J. Teste de Aptidão Física para Idosos. São Paulo: Manole, 2008

SESC - SERVIÇO SOCIAL DO COMÉRCIO. A terceira idade. Volume 16. N 33. P. 1116. São Paulo. 2005

SILVA, R. M. A. O. O idoso e a legislação brasileira: considerações acerca das garantias dadas ao idoso no Estado do Ceará. Jus.com.br. 2015. Disponível em:

$<$ https://jus.com.br/artigos/44270/o-idoso-e-a-legislacao-brasileira-consideracoes-acerca-dasgarantias-dadas-ao-idoso-no-estado-do-ceara>. Acesso em: 27 set. 2019.

VELASCO, C.G. Aprendendo a envelhecer: à luz da psicomotricidade. São Paulo: Phorte, 2006 